\title{
US Monetary Policy Rules: the Case for Asymmetric Preferences
}

\author{
Paolo Surico* \\ Bocconi University
}

November 2002

\begin{abstract}
This paper investigates the empirical relevance of a new framework for monetary policy analysis in which decision makers are allowed to weight differently positive and negative deviations of inflation and output from the target values. The specification of the central bank objective is general enough to nest the symmetric quadratic form as a special case, thereby making the derived policy rule potentially nonlinear. This forms the basis of our identification strategy which is used to develop a formal hypothesis testing for the presence of asymmetric preferences. Reduced-form estimates of postwar US policy rules indicate that the preferences of the Fed have been highly asymmetric with respect to both inflation and output gaps, with the latter being the dominant source of nonlinearity after 1983.
\end{abstract}

JEL Classification: C52, E52.

Keywords: nonlinear optimal monetary policy rules, asymmetric loss function, linearized central bank Euler equation

\footnotetext{
${ }^{*}$ WORD COUNT (including references, tables and figures): $\mathbf{7 7 2 8}$.

I am indebted to Larry Christiano, Richard Dennis, Carlo Favero, Charles Goodhart, Anton Muscatelli, Ulf Söderström and Guido Tabellini for stimulating discussions. I wish to thank seminar participants at the European Central Bank, the University of Copenhagen, and the 2002 Workshop on Macroeconomic Dynamics at the Chatolic University of Milan, as well as Stefania Albanesi, Efrem Castelnuovo, Nicola Curci, Matteo Manera, Chris Martin, Costas Milas, Tommaso Monacelli, Gaia Narciso, Giorgio Primiceri, Saverio Simonelli and Pietro Tommasino for useful comments. Address for correspondence: Istituto di Economia Politica, Università Bocconi, Via Gobbi 5, 20136 Milan, Italy. E-mail: paolo.surico@uni-bocconi.it
} 


\section{Introduction}

The last decade has been characterized by an increasing consensus in monetary policy analysis. One of the most influential paradigm has been the design of policy interventions as the constrained optimum of a well-behaved control problem in which the central bank moves interest rates to minimize some quadratic criterion. The latter defines the ultimate goals of monetary policy and translates the behavior of the target variables into some measure for policy evaluations. When assigned with such a problem, the central bank faces the constraints representing the structure of the economy. The quadratic characteristic of the objective and the linear feature of the constraints give rise to a linear first order condition according to which monetary authorities move policy rates as the optimal response to the developments in the economy.

While the quadratic specification implies that monetary authorities evenly weight positive and negative deviations of inflation and output from the target values, such a modeling choice has been questioned by several practitioners at the policy committees of various central banks on the ground that it has little justification beyond analytical tractability (see Blinder, 1997, and Goodhart, 1999). The few notable exceptions include Rotemberg and Woodford (1999) and Woodford (2002, Ch. 6) who show that the quadratic form can be obtained as a second order approximation of the utility-based welfare function. More generally, a number of quadratic objectives have been recently proposed in the literature as a way to evaluate alternative targeting schemes and the policy recommendations have been implicitly drawn upon the assumption of symmetric central bank preferences. ${ }^{1}$

Several recent studies however explore some novel mechanism through which the costs of the business cycle can be asymmetric. Galì, Gertler and Lopez-Salido (2002) construct a theoretical measure of welfare gap for the US based on price and wage markups, and show that the costs of output fluctuations have been historically large and asymmetric. Erosa and Ventura (2002) introduce transaction costs and heterogeneity in portfolio holdings in a neoclassical model of the business cycle and find that those frictions make the costs of inflation variation asymmetric. The psychology of choice suggests that people tend to place a greater weight on the prospect of losses than on the prospect of gains in decision making under uncertainty (see Kahneman and Tversky, 1979). Then, mutatis mutandis, policy makers who aggregate over individual welfare may be loss-averse with respect to both inflation and output. Lastly, as argued by Blinder (1997) the different political pressures faced by the central bank over the business cycle are likely to translate into asymmetric interest rate responses.

\footnotetext{
${ }^{1}$ See for instance Rudebusch and Svensson (1999), Dennis (2002), Söderström (2001) and Walsh (2002).
} 
Despite of its intuitive appeal, only few studies have attempted to identify asymmetric central bank behaviors and the relevance of this alternative framework remains to be assessed. Chadha and Schellekens (1999) study the implications of nonquadratic loss functions in the face of additive and multiplicative uncertainty, and find that asymmetric preferences are not sufficient to deliver a gradualist path of interest rates. Gerlach (2000), Dolado, Maria-Dolores and Naveira (2002), and Martin and Milas (2001) show some international evidence that supports the notion of asymmetric reaction functions. Ruge-Murcia (2002), and Cukierman and Muscatelli (2002) study analytically the implicit functional form of a nonlinear policy rule and conclude that the qualitative features of some G7 economy reaction functions are consistent with an asymmetric objective. Dolado, Maria-Dolores and Ruge-Murcia (2002) estimate an interest rate rule which is drawn upon the existence of asymmetric preferences on inflation only, and find that US monetary policy can be characterized by a nonlinear reaction function after 1983, but not before 1979 .

This paper contributes to the theoretical and empirical literature on optimal monetary policy rules in different respects. First, assuming a fairly general specification of both inflation and output objectives, we derive a closed-form solution of the optimal monetary policy within a New-Keynesian model of the business cycle. Since our objective function nests the conventional quadratic form as a special case, the specification of the policy rule is shown to be nonlinear if and only if the central bank preferences are asymmetric. This condition delivers a formal theoretical prediction which can be successfully tested for. Second, the analytical approach to the solution of the central bank optimal control problem allows to identify the degree of nonlinearities and asymmetries with respect to both inflation and output gaps, a result that to our knowledge of the existing literature comes as new. Third, a linearized version of the model predicts that the monetary authorities respond not only to the level of inflation and output gaps (as suggested by Taylor, 1993) but also to their squared values. Fourth, reduced-form estimates of US monetary policy rules indicate that nonlinearity is a robust feature of the data over both the pre- and post-Volcker periods. While this finding enriches the picture provided by Clarida, Galì and Gertler (2000), it suggests that the preferences of the Fed have been highly asymmetric in both inflation and output gaps, with the asymmetries on the latter becoming more pronounced than those on the former after 1983.

The road map of the paper is as follows. Section 2 presents the theoretical model and derives the interest rate rule as the first order condition of the central bank optimal control problem. The identification method and the hypothesis testing strategy for the presence of asymmetric preferences are described in Section 3. Reduced-form estimates on postwar US data are reported and discussed in the following part while the last Section concludes. 


\section{Theoretical model: a New-Keynesian perspective}

We assume that the central bank conducts monetary policy through a targeting rule according to the terminology of Svensson (1999). Thus, all available information are used to bring at each point in time the target variables in line with their targets by penalizing any future deviation of the former from the latter. The policy rule is modeled as the outcome of an intertemporal optimization problem in which decision makers minimize a given criterion under the constraints provided by the structure of the economy. The optimizing device allows us to reversely engineer the objectives of the monetary authorities, which are unobservable, from the observed path of policy rates implying that evidence on the latter can be interpreted as informative about the former. Since our identification strategy relies on the estimation of a model-based specification for the reaction function, we challenge the assumption of symmetric policy preferences in the context of a popular framework for monetary policy analysis. This is a version of the celebrated New-Keynesian model of the business cycle derived in Yun (1996), and Woodford (2002, Ch. 3 and 4), among others.

\subsection{The structure of the economy}

This subsection describes an aggregate version of the New-Keynesian forward-looking model with sticky prices that has been recently summarized by Clarida, Galì and Gertler (1999). The evolution of the state variables is compactly represented by the following two-equation system:

$$
\begin{gathered}
\pi_{t}=\theta E_{t} \pi_{t+1}+k y_{t}+\varepsilon_{t}^{s} \\
y_{t}=E_{t} y_{t+1}-\varphi\left(i_{t}-E_{t} \pi_{t+1}\right)+\varepsilon_{t}^{d}
\end{gathered}
$$

Equation (1) captures in a log-linear fashion the staggered feature of a Calvo-type world in which each firm adjusts its price with a constant probability in any given period, and independently from the time elapsed from the last adjustment. The discrete nature of price setting creates an incentive to adjust prices by more the higher is the future inflation expected at time $t$. The inflation level is $\pi_{t}$ whereas the output gap is denoted by $y_{t}$ and captures the movements in marginal costs associated with variations in excess demand. Equation (2) is a log-linearized version of a standard Euler equation for consumption combined with the relevant market clearing condition. It basically brings the notion of consumption smoothing into an aggregate demand formulation by making output gap a positive function of its expected future value and a negative function of the real interest rate, $i_{t}-E_{t} \pi_{t+1}$. Lastly, $\varepsilon_{t}^{s}$ and $\varepsilon_{t}^{d}$ are a well-behaved cost shock and demand shock, respectively. 


\subsection{An asymmetric specification of the loss function}

An important aspect of monetary policy making in such a model is that policy actions are taken before the realization of economic shocks and therefore before the state variables are determined. Accordingly, the central bank objective is to choose a path for interest rates at the beginning of period $t$ conditional upon the information available at the end of the previous period. This timing device is captured by the following intertemporal criterion:

$$
\underset{\left\{i_{t}\right\}}{\operatorname{Min}} E_{t-1} \sum_{\tau=0}^{\infty} \delta^{\tau} L_{t+\tau}
$$

where $\delta$ is the discount factor and $L$ stands for the period loss function.

Our framework differs from the conventional quadratic set up in that we employ a more general specification of the monetary authorities' objectives. Indeed, the quadratic form may approximate reasonably well a number of different functions and in the absence of a rigorous theoretical foundation any specific nonquadratic proposal is destined to be unsatisfactory against the wide range of plausible alternatives. Hence, rather than attempting to uncover the correct functional form of policy makers' preferences, we evaluate the symmetric quadratic paradigm upon the empirical merits of the monetary policy rule that this specification implies. With this descriptive scope in mind, we write $L_{t}$ as follows:

$$
L_{t}=\frac{e^{\left[\alpha\left(\pi_{t}-\pi^{*}\right)\right]}-\alpha\left(\pi_{t}-\pi^{*}\right)-1}{\alpha^{2}}+\lambda\left[\frac{e^{\left(\gamma y_{t}\right)}-\gamma y_{t}-1}{\gamma^{2}}\right]+\frac{\mu}{2}\left(i_{t}-i^{*}\right)^{2}
$$

The coefficients $\lambda$ and $\mu$ represent the central bank's aversion towards output fluctuations around potential and interest rate level fluctuations around the target $i^{*}$. The policy preference towards inflation stabilization is normalized to one and therefore $\lambda$ and $\mu$ are expressed in relative terms. The inflation target is $\pi^{*}$ whereas the parameters $\alpha$ and $\gamma$ capture any asymmetry in the objective function of the monetary authorities.

The linex specification in (4), which has been originally proposed by Varian (1974) and Zellner (1986) in the context of Bayesian econometric analysis and introduced by Nobay and Peel (1998) in the optimal monetary policy literature, embodies a number of appealing characteristics. First, it allows for departures from the quadratic objective in that policy makers may treat differently positive and negative deviations of the target variables from the reference values. This pattern is shown in Figure 1 which plots the standard quadratic versus the asymmetric function for both inflation (Panel a) and output gap (Panel b).

The key difference between the two specifications is that deviations of the same size yield different losses. Indeed, under the symmetric scenario policy makers are assumed to care 
only about the magnitude of deviations whereas under asymmetric preferences they care also about the sign. In particular, a positive value of $\alpha$ in Panel (a) implies that, everything equals, deviations of inflation (relative to target) from above are weighted more severely than deviations from below. To see this notice that whenever $\pi_{t}-\pi^{*}>0$ the exponential component of the loss function dominates the linear component while the converse is true for $\pi_{t}-\pi^{*}<0$. The same reasoning holds for the coefficient $\gamma$ in Panel (b), which captures any asymmetry in the policy preferences for stabilizing the business cycle. However, if monetary authorities are more concerned about undershooting potential output rather than overshooting it, the value of $\gamma$ would be negative implying that whenever $y<0$ the loss rises exponentially whereas it does linearly for $y>0$.

Furthermore, the linex loss function specified above is so general as to collapse to the symmetric quadratic form for some parameter limiting case. Applying twice L'Hôpital's rule on (4), it is possible to show that whenever $\alpha$ and $\gamma$ tend to zero the central bank objective function reduces to the symmetric parametrization $L_{t}=\frac{1}{2}\left[\left(\pi_{t}-\pi^{*}\right)^{2}+\lambda y_{t}^{2}+\mu\left(i_{t}-i^{*}\right)^{2}\right]$. The latter can be obtained as a quadratic approximation of the utility-based welfare function in a New-Keynesian model of the business cycle that involves a zero lower bound for nominal interest rate (see Woodford, 2002, Ch. 6). Accordingly, the policy preferences would be functions of some primitive parameters of the model implying that potential evidence of asymmetries in the central bank objective could be tracked into evidence of asymmetries in the representative agent's utility. Indeed, as argued by Clarida, Galì and Gertler (1999), the representative agent approach can be highly misleading as a guide to welfare analysis and it is likely to be the case that some groups suffer more in recessions or in high inflation periods than others. This suggests that an asymmetric utility-based specification of the loss function may be a desirable representation of the social costs of cyclical fluctuations.

\subsection{A nonlinear policy rule}

We let monetary authorities choose policy rates in a discretionary fashion. Indeed, the case for an optimal monetary policy without commitment seems to be closer to the actual practice of many central banks which rarely tie their hands over the course of future policy actions. Because no endogenous state variable enters the model, the intertemporal policy problem reduces to a sequence of static optimization problems. This amounts to choosing in each period the instrument rate such as to minimize:

$$
E_{t-1}\left(\frac{e^{\left[\alpha\left(\pi_{t}-\pi^{*}\right)\right]}-\alpha\left(\pi_{t}-\pi^{*}\right)-1}{\alpha^{2}}\right)+\lambda E_{t-1}\left[\frac{e^{\left(\gamma y_{t}\right)}-\gamma y_{t}-1}{\gamma^{2}}\right]+\frac{\mu}{2}\left(i_{t}-i^{*}\right)^{2}+F_{t}
$$


subject to $\pi_{t}=k y_{t}+f_{t}$ and $y_{t}=-\varphi i_{t}+g_{t}$ where $F_{t} \equiv E_{t-1} \sum_{\tau=1}^{\infty} \delta^{\tau} L_{t+\tau}, f_{t} \equiv \theta E_{t} \pi_{t+1}+\varepsilon_{t}^{s}$ and $g_{t} \equiv E_{t} y_{t+1}+\varphi E_{t} \pi_{t+1}+\varepsilon_{t}^{d}$ are taken as given reflecting the fact that monetary authorities cannot directly manipulate expectations. The first order condition reads

$$
-E_{t-1}\left(\frac{e^{\left[\alpha\left(\pi_{t}-\pi^{*}\right)\right]}-1}{\alpha}\right) k \varphi-E_{t-1}\left(\frac{e^{\left(\gamma y_{t}\right)}-1}{\gamma}\right) \lambda \varphi+\mu\left(i_{t}-i^{*}\right)=0
$$

which is a closed-form solution for the optimal policy rule. Equation (5) implicitly describes a general reaction function according to which the central bank moves policy rates as the optimal, potentially nonlinear, response to the developments in the economy. ${ }^{2}$ The important result which underlies equation (5) is that it nests the conventional linear form as a special case. Indeed, it can be shown by means of L'Hôpital's rule that when both $\alpha$ and $\gamma$ tend to zero the reaction function (5) collapses to an implicit interest rate rule of the type proposed by Rudebusch (2002), and Clarida, Galì and Gertler (2000):

$$
-k \varphi E_{t-1}\left(\pi_{t}-\pi^{*}\right)-\lambda \varphi E_{t-1}\left(y_{t}\right)+\mu\left(i_{t}-i^{*}\right)=0
$$

This feature is attractive in that it delivers a joint restriction on policy makers' preferences which can be formally tested for. It follows that the hypothesis of symmetric loss function can be challenged by assessing whether the relevant feedback coefficients are, either jointly or marginally, significantly different from zero. The policy parameters $\alpha$ and $\gamma$ are indeed crucial for the analysis of optimal monetary policy not only because they introduce an asymmetric motive in the central bank objective function but also because, more importantly, they make those asymmetries mapping into a nonlinear policy rule. This suggests that were $\alpha$ and $\gamma$ identified, the hypothesis that central bank preferences are symmetric around the target could be tested simply by evaluating the functional form of the feedback rule as the latter would correspond to test whether $\alpha$ and $\gamma$ are significantly different from zero. Hence, evidence of nonlinearity in the policy rule would be informative about which type of asymmetry, if any, is relevant to policy makers.

\section{Econometric analysis}

The parameters $\alpha$ and $\gamma$ and the exponential function govern the asymmetric response of policy rates to positive and negative deviations of the state variables from the target. Our task consists in estimating the nonlinear reaction function (5) in order to evaluate whether

\footnotetext{
${ }^{2}$ Notice that in contrast to other studies which impose an ad-hoc partial adjustment mechanism, our modelbased reaction function does not include any lagged interest rate terms. This comes from the fact that monetary authorities pursue the stabilization of policy rate levels rather than changes, a feature which hinges upon the specification of the utility function of the representative agent (see Woodford, 2002, Ch. 6).
} 
those parameters are significantly different from zero. This amounts to test linearity against a nonlinear model, which is complicated by the fact that in small samples the estimation criterion is insensitive to the so-called smoothness coefficients as there exists a large set of $\alpha$ - and $\gamma$-values yielding almost the same interest rate behavior (see Granger and Teräsvirta, 1993, Ch. 7). It follows that the asymmetric preferences would be inaccurately estimated, thereby making the hypothesis testing for the presence of nonlinearities theoretically flawed. Moreover, the specification in (5) is nonlinear in the relevant parameters and therefore the econometric method of estimation may pick up just one among the numerous local maxima depending on the initial values of the coefficients.

A simple transformation of the model that confronts directly the issue involves the linearization of the exponential terms in (5) by means of a first-order Taylor series expansion around $\alpha=\gamma=0$. The reduced-form policy rule now reads

$$
\begin{aligned}
& -k \varphi E_{t-1}\left(\pi_{t}-\pi^{*}\right)-\lambda \varphi E_{t-1}\left(y_{t}\right)-\frac{\alpha k \varphi}{2} E_{t-1}\left[\left(\pi_{t}-\pi^{*}\right)^{2}\right]+ \\
& -\frac{\lambda \varphi \gamma}{2} E_{t-1}\left(y_{t}^{2}\right)+\mu\left(i_{t}-i^{*}\right)+e_{t}=0
\end{aligned}
$$

with $e_{t}$ being the remainder of the Taylor series approximation.

This condition relates the policy rates with the expected future levels and squared values of the state variables conditioned upon the information available at time $t-1$. We solve equation (6) for $i_{t}$ and prior to estimation we replace expected inflation and output gaps with actual values. Accordingly, we focus on the following policy rule:

$$
i_{t}=c_{\text {onst }}+c_{1} \pi_{t}+c_{2} y_{t}+c_{3}\left(\pi_{t}\right)^{2}+c_{4}\left(y_{t}\right)^{2}+v_{t}
$$

which is linear in the coefficients

$$
\begin{gathered}
c_{\text {onst }} \equiv i^{*}-c_{1} \pi^{*}-c_{3}\left(\pi^{*}\right)^{2} \\
c_{1} \equiv \frac{k \varphi}{\mu}-2 c_{3} \pi^{*} \\
c_{2} \equiv \frac{\lambda \varphi}{\mu} \\
c_{3} \equiv \frac{\alpha k \varphi}{2 \mu} \\
c_{4} \equiv \frac{\lambda \varphi \gamma}{2 \mu}
\end{gathered}
$$

and whose error term is defined as

$$
v_{t} \equiv-\left\{\begin{array}{c}
c_{1}\left(\pi_{t}-E_{t-1} \pi_{t}\right)+c_{2}\left(y_{t}-E_{t-1} y_{t}\right)+ \\
+c_{3}\left[\pi_{t}^{2}-E_{t-1}\left(\pi_{t}\right)^{2}\right]+c_{4}\left[y_{t}^{2}-E_{t-1}\left(y_{t}\right)^{2}\right]
\end{array}\right\}+\frac{e_{t}}{\mu}
$$


The term in curly brackets is a linear combination of forecast errors and therefore $v_{t}$ is orthogonal to any variable in the information set available at time $t-1$.

Equation (7) makes clear that by assuming an optimizing central bank behavior the reaction function parameters can only be interpreted as convolutions of the coefficients representing policy makers' preferences and those describing the structure of the economy. While recovering all structural parameters is beyond the scope of this paper, a single-equation estimation of the derived policy rule is all we need to identify the asymmetric preferences. Indeed, the feedback coefficients $c_{3}$ and $c_{4}$ embody the relevant information such that the joint restriction $\alpha=\gamma=0$ implies $c_{1} \neq 0, c_{2} \neq 0$ and $c_{3}=c_{4}=0$. Hence, testing the hypothesis $H_{0}: \alpha=\gamma=0$ in (5) is equivalent to testing the hypothesis $H_{0}^{\prime}: c_{3}=c_{4}=0$ in (7). ${ }^{3} \mathrm{Un}$ der the null of a linear reaction function, which fully corresponds to symmetric preferences, the test statistics has an asymptotic $\chi^{2}$ distribution with as many degrees of freedom as the number of restrictions. Such an hypothesis can be successfully evaluated through a standard Wald test and since we are considering the auxiliary null $H_{0}^{\prime}: c_{3}=c_{4}=0$ rather than the original hypothesis $H_{0}: \alpha=\gamma=0$, the statistics is usually referred to as Wald-type. ${ }^{4}$

While our strategy allows to identify the asymmetric preference on output gap, $\gamma$, from the coefficients $c_{4}$ and $c_{2}$ only, it does not allow to recover the other key preference parameter, $\alpha$, unless some additional restriction are imposed to the policy rule. Nevertheless, were $c_{3}$ and $c_{4}$ jointly significant the hypothesis on symmetric preferences would be rejected. We will return on the issue in the next section.

Lastly, it should be noticed that while the nonlinear quadratic terms in (7) stem from asymmetric central bank preferences, we cannot exclude in principle that a nonlinear Phillips curve be indeed responsible for any reduced-form evidence of nonlinearity. A simple way to discriminate between nonquadratic objectives and nonlinear constraints is to perform the REgression Specification Error Test (RESET), which is designed to detect incorrect functional forms, on the New-Keynesian Phillips curve. Accordingly, we estimate equation (1) on US 1960:1-2001:4 quarterly data using the Generalized Method of Moments (GMM) with a 12lag Newey-West variance covariance matrix. The set of instruments include four lags of GDP chain-weighted inflation, Congressional Budget Office output gap, long-short interest rate spread, and consumer price inflation. When the squares and then the squares and the cubes of the predictions $\hat{\pi}_{t}$ are added to the original equation, the corresponding F-tests show that

\footnotetext{
${ }^{3}$ It is worthwhile to notice that the power of the test upon the auxiliary regression (7) crucially depends on the significance of $c_{1}$ and $c_{2}$ as it may be the case that $H_{0}^{\prime}$ cannot be rejected simply because $c_{1}$ and $c_{2}$ are not statistically different from zero.

${ }^{4}$ As we are estimating a model which is linear in the parameters, the critique that the Wald test for nonlinear specifications is not invariant to the parametrization of the model simply does not apply here.
} 
the null hypothesis of non-misspecification cannot be rejected. This suggests that the US aggregate supply curve is well approximated by a linear relation, thereby making asymmetric preferences the most empirically relevant source of nonlinearity over the sample. Empirical support for a linear US Phillips curve can also be found in Dolado, Maria-Dolores and RugeMurcia (2002), and Dolado, Maria-Dolores and Naveira (2002).

\section{Empirical results}

This section reports the estimates and the relevant tests of the policy reaction function (7). The analysis is conducted on US quarterly data spanning the period 1960:1-2001:4. The data set has been obtained from the web site of the Federal Reserve Bank of St. Louis and embodies alternative measures of inflation and output gap. In particular, the baseline measure of inflation is constructed from the (log) GDP chain-weighted price index while the one for output gap is taken from the Congressional Budget Office. As a way of providing a robustness check, we also report the results for two alternative measures of the state variables, namely the consumer price index inflation and the detrended output obtained as the residuals from regressing output on a constant and a quadratic trend.

We divide the full sample around the third quarter of 1979 which corresponds to the appointment of Paul Volcker as Fed Chairman. This lines up with a number of empirical studies that demonstrate a significant difference in the way monetary policy was conducted pre- and post-1979 (see Clarida, Galì and Gertler, 2000, Judd and Rudebusch, 1998, and Dennis, 2002 among others). Moreover, we remove from the second sub-sample the period 1979:3- 1982:3 when, as documented by Bernanke and Mihov (1998), the operating procedure of the Fed temporarily switched from Fed funds rate to non-borrowed reserves. Finally, we address the issue of subsample stability by re-evaluating the model over the Chairmanship of Alan Greenspan, 1987:3-2001:4.

The empirical analysis maintains the assumption that the model variables are stationary. Although the null of unit root is often hard to reject, the well known low power of those tests and the documented change of policy regime make it a reasonable hypothesis for the postwar US (see Clarida, Galì and Gertler, 2000).

We estimate equation (7) over the three periods using GMM with an optimal weighting matrix that accounts for possible heteroskedasticity and serial correlation in the error terms (see Hansen, 1982). In practice, we employ a four lag Newey-West estimate of the covariance matrix. Four lags of the explanatory variables, the interest rates and the measure of inflation left out from the regression are included as instruments corresponding to a set of 20 
overidentifying restrictions that can be tested for. ${ }^{5}$

In the absence of further assumptions our approach only identifies the policy parameter on output gap asymmetries, $\gamma$, but neither the one on inflation, $\alpha$, nor the inflation target, $\pi^{*}$, separately. Since the focus of our analysis is on the former parameters, we impose prior to estimation the additional restriction that the observed subsample average of inflation provides a reasonable approximation of the target. This assumption, which is consistent with the estimates provided by Judd and Rudebusch (1998), and Clarida, Galì and Gertler (2000), allows to jointly identify $\alpha$ and $\gamma$ while making the feedback coefficients free from $\pi^{*} .{ }^{6}$ On the contrary, no additional restrictions are needed for our hypothesis testing strategy on symmetric central bank preferences.

\subsection{Baseline estimates}

Table 1 reports the GMM estimates of the feedback coefficients as well as the relevant parameters on asymmetric behavior for the baseline case corresponding to GDP chain-type inflation and CBO output gap. The policy preferences $\gamma$ and $\alpha$, which feature an asymmetric loss function, have the expected signs and they are marginally significant throughout the table with the exception of $\alpha$ for the second subsample. A remarkable shift in output gap asymmetries is observed between the pre- (first column) and the post-Volcker (second column) regimes in that $\gamma$ moves to an absolute value bigger than one in the latter period (we will return on the third column in the following subsection). All feedback coefficients but the one on squared inflation in the second subsample are significantly different from zero and they allow us to perform the crucial hypothesis testing of our analysis.

The first row of Table 2 shows that the null hypothesis of a linear reaction function, which corresponds to the joint null of symmetric central bank preferences, is strongly rejected over the two periods with the Wald statistics being much larger than the relevant critical value ${ }^{7}$ (disregard the last two columns for the time being). Lastly, it can be argued that potential

\footnotetext{
${ }^{5}$ Notice that because no lagged interest rate terms appear in (7) as explanatory variable, the error component is likely to be serially correlated. This is more that a standard error issue as it implies a violation of the orthogonality conditions stemming from the New-Keynesian transmission mechanism. We solve the issue by removing from the set of instruments so many lags as to make the residuals nonsystematic. This amounts to replace the first lag of each instrument in the pre-79 period and the first three lags in the post-79 period with their own earlier lags. An F-test applied to the first-stage regression rejects the hypothesis of weak instruments.

${ }^{6}$ Indeed, under asymmetric central bank preferences the inflation conditional mean may be either below or above the inflation target depending, inter alia, on the relative size of the policy parameters on inflation and output gaps (see Nobay and Peel, 1998, Ruge-Murcia, 2002, and Cukierman, 2001, for a formal derivation of this novel inflation bias). However, under the null of symmetric preferences such a bias disappears (i.e. average inflation equals inflation target), thereby preserving the validity of our hypothesis testing strategy.

${ }^{7}$ The results are unaffected by two robustness checks. The first uses $F$-versions of the Wald statistics as opposed to the $\chi^{2}$ variants which may be oversized in small samples. The second adds a cubic term for inflation and output gap as implied by a second-order Taylor expansion of the nonlinear policy rule.
} 
measurement errors for the state variables are likely to affect the point estimates of the reaction function and most importantly the power of the test for the presence of nonlinearities. However, Kuha and Temple (2002) show that measurement error in quadratic regression tends to hide the presence of nonlinearities, thereby making stronger the case for asymmetric preferences and suggesting that our estimates are better interpreted as a lower bound.

\subsubsection{Comparison to other empirical estimates and subsample stability}

It is useful at this point to compare our results with the empirical estimates obtained in other recent studies in order to gauge their plausibility. In the pre-Volcker period, Clarida, Galì and Gertler (2000) estimate a forward-looking linear reaction function with an ad-hoc adjustment mechanism and find values of 0.83 for the coefficient on inflation (s.e. $=0.07$ ) and 0.27 for the coefficient on output (s.e.=0.08). The significant difference comes from the output gap parameter which suggests that neglecting the quadratic term, which enters our empirical specification with a negative sing, introduces a downward bias in the linear estimate. Turning to a nonlinear specification, Dolado, Maria-Dolores and Ruge-Murcia (2002) use a Clarida, Galì and Gertler-type rule augmented with a generated regressor for the conditional variance of inflation and estimate the marginal impact of inflation at 1.14 (s.e. $=0.12$ ) and the one of output at 0.31 (s.e. $=0.11$ ). In addition to the downward bias for the output level, their findings suggest that neglecting the quadratic terms introduce also an upward bias for the coefficient on inflation level, which is consistent with the positive estimate we get for the squared inflation.

The picture is completed by the post-Volcker estimates. Both coefficients on inflation level and output level display differences of expected sign relative to the values reported in Clarida, Galì and Gertler (2000) while they are consistent with those provided by Dolado, Maria-Dolores and Ruge-Murcia (2002). Lastly, we line up with early contributions in that the coefficient on the inflation level becomes bigger than one moving from the pre- to the post-Volcker era.

It should be noticed that as no lagged policy rate terms enter the nonlinear interest rate rule (7), our estimates should be interpreted as long-run responses. Interestingly, they can also be interpreted as short-run coefficients if one is willing to consider monetary policy inertia as an illusion reflecting the episodic unforecastable persistent shocks that central banks face. In this vein, Rudebusch (2002) use our baseline measure of inflation and output gap over the period 1987:4-1999:4 to estimate with instrumental variables a linear forward-looking US monetary policy rule which is all alike equation (7) but the squared variables. In order to make our estimates directly comparable with those in Rudebusch (2002), we re-evaluate the 
nonlinear policy rule over the Greenspan sample. In so doing, we can also assess the robustness of our results to subsample stability.

The estimates are reported in the third column of Table 1 and they reinforce the findings obtained so far. Indeed, not only all parameters are statistically different from zero and take the expected sign but also the coefficient on inflation asymmetries becomes now significant. The value of $\gamma$ keeps growing over time confirming a significant shift in the Fed output preferences across the pre- and post-Volcker tenures, while the Wald statistics rejects the null of symmetric preferences with a value of 83.883 .

Turning to the comparison to other empirical estimates, we observe that neglecting the squared variables introduces once more a significant omitted variable bias. In particular, the estimates provided in Rudebusch (2002) read the parameter on inflation levels at 2.00 (with s.e. $=0.66$ ) and the one on output gap levels at 0.39 (with s.e. $=0.24$ ). By contrast, the results we report in Table 1 shows that the point estimate of $c_{1}$ is significantly reduced whenever the policy rule incorporates a squared inflation term whereas $c_{2}$ becomes higher whenever a squared output gap term is allowed for. While part of the differences can be attributed to both the longer sample and the non-annualized quarterly inflation we use, our results seem to suggest a significant role for the nonlinear components of US monetary policy rules. Such a conclusion mirrors the estimates by Cukierman and Muscatelli (2002) who, employing an ad-hoc specification for the reaction function over a slightly longer sample, find a positive and significant coefficient for the nonlinear inflation term and a negative and significant coefficient for the nonlinear output component.

\subsection{Robustness analysis}

We assess now in turn the robustness of our findings to alternative measures of inflation and output gap. Table 3 reports the estimates obtained with GMM using, everything equals, the changes in the consumer price index as measure of inflation. All preference parameters on asymmetries have the expected sign. In analogy to the results in Table 1, the coefficient $\gamma$ on output gap displays a substantial growth over time in absolute values, although it is less pronounced than for the GDP chain-type inflation. All reaction function coefficients are significant but $c_{4}$ in the pre-Volcker period, which translates into a nonsignificant value of $\gamma$. The asymmetric preference parameter on inflation is still not statistically different from zero over the second sample. Nevertheless, the Wald statistics displayed in the second row of Table 2 show that the joint null hypothesis of a linear policy rules is strongly rejected over both samples.

We re-estimate the policy rule(7) using GDP chain-type inflation and detrended output 
as measures of the state variables. The results are shown in Table 4 and they mirror those of previous tables over the pre-79 regime. In particular, significant values of the feedback coefficients map into significant values of the asymmetric parameters, which once more display the expected signs. Turning to the post-Volcker period, a different picture emerges. While the preference parameter $\gamma$ is still negative and significant and confirms in absolute values its growing path over time, the coefficient $\alpha$ on inflation asymmetries takes now a negative and significant value. However, the relevance of the latter result has to be weighted by the fact that detrended output may be not an appropriate measure of the business cycle. ${ }^{8}$

We complete the robustness analysis by introducing an interest rate smoothing argument into the nonlinear policy rule to evaluate whether the Fed tendency to smooth policy rates may turn out to be responsible for a seemingly nonlinear behavior. ${ }^{9}$ The estimates of the policy preferences line up with those of the baseline case while the last row of Table 2 shows that the null of symmetric preferences is once more strongly rejected over both samples. This finding suggests that squared inflation and squared output gap capture a genuine nonlinear behavior and therefore they have a place on their own right in US monetary policy rules. ${ }^{10}$

\subsection{Discussion}

A number of different results stem from the estimates reported above. On the one hand, the preference parameter on output asymmetries, whose identification does not require any additional assumption on the model coefficients, takes negative and significant values. Such an evidence is robust across alternative measures of inflation and output gaps being consistent with an asymmetric specification of the central bank objectives. In addition, the significant increase of $\gamma$ over time appears to be a robust feature of the data corroborating the view that a regime shift has occurred between the pre- and the post-1979 Chairmen. On the other hand, the estimates on the inflation preference parameter, $\alpha$, take a positive sign and they are significantly different from zero mainly over the first sample.

These findings enrich the picture provided by Clarida, Galì and Gertler (2000) and indicate that nonlinearity has significantly characterized the postwar policy stance of the Fed. Indeed, equation (7) makes clear that under asymmetric preferences the interest rate responses are

\footnotetext{
${ }^{8}$ Indeed, as argued by McCallum and Nelson (1999), not only the fitted trend displays a significantly more volatile path than the CBO time series, especially during the post-Volcker period, but also it does not capture the conventional wisdom that output has been unusually high relative to potential in the mid-90s.

${ }^{9}$ Estimates of the reaction function and the preference parameters in the presence of interest rate smoothing are not reported here to save space, but they are available from the author upon request.

${ }^{10}$ Surico (2002) shows that these results are robust to both a backward-looking structure of the economy à la Rudebusch and Svensson (1999) and to a nonparametric specification of the central bank loss function. In particular, the nonparametric estimates suggest that the nonlinearities found in US monetary policy rules are consistent with an objective function that is both nonquadratic and asymmetric.
} 
not anymore time invariant but rather they depend on the level of inflation and output gaps. Accordingly, large deviations of the target variables require vigorous movements of policy rates whereas small deviations require only limited changes. This point is illustrated in Figure 2 and 3 which compare our baseline estimates with those obtained using a linear specification of the policy rule (i.e. forcing $c_{3}$ and $c_{4}$ to be zero). The vertical axis displays the interest rate responses (relative to target) implied by the estimates of the two rules while the horizontal axis reports the actual movements over the Greenspan sample for inflation and output gaps respectively. The graphs show not only that US monetary policy has been significantly nonlinear and asymmetric but also that large gaps have been penalized more than small gaps with the exception of the negative deviations of inflation.

Furthermore, Figure 3 shows that only according to the nonlinear policy rule interest rates have been lowered in response to both positive and negative output gaps with the former mostly corresponding to the period 1997:1-2001:1. Interestingly, this observation is consistent with the view that the Fed has taken advantage of the benign macroeconomic conditions of the late 90s to accommodate the favorable supply shocks that the 'New Economy' has brought about. ${ }^{11}$ It should be noticed that the reversed U-shape policy response displayed in Figure 3 is a feature of the post-Volcker era only since over the first sample the relative size of $c_{2}$ over $c_{4}$ is considerably higher in absolute value than its post-79 counterpart (see Table 1). Indeed, while the squared term translates into a significant asymmetric behavior also over the pre-79 sample, the coefficient on levels, which is now bigger than one, makes the nonlinear relation between interest rates and output gap positive over the entire domain.

Lastly, a comparison of $\alpha$ and $\gamma$ across samples shows that output asymmetries have become relatively more pronounced during the post-Volcker tenures. In particular, the presence of highly asymmetric preferences on output seems to rationalize the sequences of downwards movements through which the Fed has considerably cut interest rates during 2001.

\section{Conclusions}

The contribution of this paper is twofold. At the theoretical level it derives a general closedform solution for interest rate rules when central bank preferences are asymmetric in both inflation and output gaps, and the monetary transmission mechanism is New-Keynesian. The specification of the policy objectives nests the quadratic form as a special case and therefore

\footnotetext{
${ }^{11}$ Notice that by using the $(\mathrm{CBO})$ output gap as opposed to the unemployment rate we have implicitely specified a time-varying target for the stabilization of the business cycle. Moreover, since the potential output series is constructed upon revised data, the argument that a shift in the NAIRU estimates may have warranted such a seemingly nonlinear behavior does not apply here.
} 
it translates into a potentially nonlinear monetary policy rule. This modeling feature forms the basis of our hypothesis testing strategy for the presence of asymmetric preferences as it allows to reversely engineer potential evidence of nonlinearities in the reaction functions into evidence of asymmetries in the policy objectives.

At the empirical level this paper shows that US monetary policy can be characterized by a nonlinear policy rule during both the pre- and post-Volcker eras, with the interest rate responses to the state of the business cycle being the dominant form of nonlinearity over the second sample. Moreover, our identification method indicates that the preferences of the Fed have been highly asymmetric with respect to both inflation and output gaps, and that the asymmetries on the latter have become relatively more pronounced after 1983. These findings are robust across alternative measures of inflation and output gap as well as to the existence of an interest rate smoothing goal in the central bank loss function.

Altogether, this paper develops a formal hypothesis testing for the presence of asymmetric preferences. As the null of the test features the quadratic form used in earlier contributions, our results suggest some caution about using symmetric loss functions as a guide to policy analysis. Indeed, promising strands of literature have recently emphasized that labor market frictions and heterogeneity in portfolio holdings can make the welfare costs of business fluctuations and inflation asymmetric. Along these lines, a stimulating avenue for future research is to derive an utility-based welfare function within richer models of the business cycle in order to provide a formal microfoundation for an asymmetric central bank objective. The proposal by Geraats (1999) comes as an intriguing step in this direction. 


\section{References}

Barro, R.J. and D. Gordon, 1983, A Positive Theory of Monetary Policy in a Natural Rate Model, Journal of Political Economy 91, 589-610.

Bernanke, B. and I. Mihov, 1998, Measuring Monetary Policy, Quarterly Journal of Economics $63,869-902$.

Blinder, A., 1997, Distinguished Lecture on Economics and Government: What Central Bankers Could Learn from Academics and Viceversa, Journal of Economic Perspective 11, 3-19.

Chadha, J.S. and P. Schellekens, 1999, Monetary policy loss functions: two cheers for the quadratic, DAE Working Paper 99/20.

Clarida, R., J. Galì and M. Gertler, 2000, Monetary Policy Rules and Macroeconomic Stability: Evidence and Some Theory, Quarterly Journal of Economics 115, 147-180.

Clarida, R., J. Galì and M. Gertler, 1999, The Science of Monetary Policy: A New Keynesian Perspective, Journal of Economic Literature 37, 1661-1707.

Cukierman, A, and V.A. Muscatelli, 2002, Do Central Banks have Precautionary Demands for Expansions and for Price Stability? - Theory and Evidence, mimeo, Tel-Aviv University.

Cukierman, A., 2001, The Inflation Bias Result Revisited, mimeo, Tel-Aviv University.

Dennis, R., 2002, The Policy Preferences of the US Federal Reserve. Federal Reserve of San Francisco Working paper No. 2001-08.

Dolado, J.J., R. Maria-Dolores and M. Naveira, 2002, Are Monetary-Policy Reaction Functions Asymmetric? The Role of Nonlinearity in the Phillips Curve, mimeo, Universidad Carlos III de Madrid.

Dolado, J.J., R. Maria-Dolores and F.J. Ruge-Murcia, 2002, Nonlinear Monetary Policy Rules: Some New Evidence for the US, CEPR Discussion paper No. 3405.

Erosa, A. and G. Ventura, 2002, On Inflation as a Regressive Consumption Tax, Journal of Monetary Economics 49, 761-795.

Galì, J., M. Gertler and J.D. Lopez-Salido, 2002, Markups, Gaps, and the Welfare Costs of Business Fluctuations, mimeo, Universitat Pompeu Fabra.

Geraats, P., 1999, Inflation and Its Variation: An Alternative Explanation, CIDER Working Paper C99-105.

Gerlach, S., 2000, Asymmetric Policy Reactions and Inflation, mimeo, BIS.

Goodhart, C.A.E., 1999, Central Bank and Uncertainty, Bank of England Quarterly Bulletin February, 102-121.

Granger, C.W.J. and T. Teräsvirta 1993, Modelling Non-linear Economic Relationship, (Oxford University Press).

Hansen, L.P., 1982, Large Sample Properties of Generalized Method of Moments Estimators. Econometrica 50, 1029-1054. 
Judd, J.P. and G.D. Rudebusch, 1998, Taylor's rule and the Fed: 1970-1997, Federal Reserve Bank of San Francisco, Economic Review 3, 3-16.

Kahneman, D. and A., Tversky, 1979, Prospect Theory: An Analysis of Decision under Risk, Econometrica 47, 263-292.

Kuha, J. and J. Temple, 2002, Covariate Measurement Error in Quadratic Regression, mimeo, University of Bristol.

Martin, C. and C. Milas, 2001, Modelling Monetary Policy: Inflation Targeting in Practice, mimeo, Brunel University.

McCallum, B. and E. Nelson, 1999, Performance of Operational Policy Rules in an Estimated Semiclassical Structural Model, in: Taylor, J.B., ed., Monetary Policy Rules, (Chicago University press).

Nobay, R. and D. Peel, 1998, Optimal Monetary Policy in a Model of Asymmetric Central Bank Preferences, mimeo, London School of Economics.

Rotemberg, J.J. and M. Woodford, M., 1999, Interest Rate Rules in an Estimated Sticky Price Model, in: Taylor, J.B., ed., Monetary Policy Rules, (Chicago University press).

Rudebusch, G.D., 2002, Term Structure Evidence on Interest Rate Smoothing and Monetary Policy Inertia, Journal of Monetary Economics 49, 1161-1187.

Rudebusch, G.D. and L.E.O. Svensson, 1999, Policy Rules for Inflation Targeting, in: Taylor, J.B., ed., Monetary Policy Rules, (Chicago University press).

Ruge-Murcia, F.J., 2002, The Inflation Bias when the Central Banker Targets the Natural Rate of Unemployment, European Economic Review, forthcoming.

Söderström, U., 2001, Targeting Inflation with a Prominent Role for Money, Sveriges Riksbank working Paper No. 123.

Surico, P., 2002. Asymmetric Central Bank Preferences and Nonlinear Policy Rules, Bocconi University working paper EEA 02-5.

Svensson, L.E.O., 1999, Inflation Targeting as a Monetary Policy Rule, Journal of Monetary Economics, 43, 607-654.

Taylor, J.B., 1993, Discretion versus Policy Rules in Practice, Carnegie-Rochester conference series on public policy 39, 195-214.

Varian, H., 1974, A Bayesian Approach to Real Estate Assessment, in: Feinberg, S.E., and A. Zellner, eds., Studies in Bayesian Economics in Honour of L.J. Savage (North Holland).

Walsh, C., 2002, Speed Limit Policies: The Output Gap and Optimal Monetary Policy, American Economic Review, forthcoming.

Woodford, M., 2002, Interest and Prices: Foundations of a Theory of Monetary Policy, forthcoming, (Princeton University Press).

Yun, T., 1996, Nominal Price Rigidity, Money Supply Endogeneity, and Business Cycles, Journal of Monetary Economics 37, 345-370.

Zellner, A., 1986, Bayesian Estimation and Prediction Using Asymmetric Loss Functions, Journal of the American Statistical Association 81, 446-451. 
Table 1: Reaction Function and Policy Preferences Estimates

- baseline measures of inflation and output gap -

\begin{tabular}{|c|c|c|c|}
\hline & 1960:1 - 1979:2 & 1982:4 2001:4 & $1987: 3-2001: 4$ \\
\hline const & $\begin{array}{c}4.214 \\
(0.241)\end{array}$ & $\begin{array}{c}7.145 \\
(0.293)\end{array}$ & $\begin{array}{c}6.305 \\
(0.235)\end{array}$ \\
\hline$c 1$ & $\begin{array}{c}0.853 \\
(0.061)\end{array}$ & $\begin{array}{c}1.742 \\
(0.185)\end{array}$ & $\begin{array}{c}1.213 \\
(0.191)\end{array}$ \\
\hline$c 2$ & $\begin{array}{c}1.108 \\
(0.095)\end{array}$ & $\begin{array}{c}0.621 \\
(0.101)\end{array}$ & $\begin{array}{c}0.549 \\
(0.077)\end{array}$ \\
\hline$c 3$ & $\begin{array}{c}0.093 \\
(0.023)\end{array}$ & $\begin{array}{c}0.047 \\
(0.203)\end{array}$ & $\begin{array}{c}0.475 \\
(0.174)\end{array}$ \\
\hline$c 4$ & $\begin{array}{c}-0.138 \\
(0.017)\end{array}$ & $\begin{array}{c}-0.455 \\
(0.078)\end{array}$ & $\begin{array}{c}-0.474 \\
(0.052)\end{array}$ \\
\hline$\pi^{*}$ & $\begin{array}{c}4.432 \\
-\end{array}$ & $\begin{array}{c}2.585 \\
-\end{array}$ & $\begin{array}{c}2.423 \\
-\end{array}$ \\
\hline$\gamma$ & $\begin{array}{l}-0.249 \\
(0.017)\end{array}$ & $\begin{array}{l}-1.464 \\
(0.337)\end{array}$ & $\begin{array}{c}-1.725 \\
(0.370)\end{array}$ \\
\hline$\alpha$ & $\begin{array}{c}0.218 \\
(0.060)\end{array}$ & $\begin{array}{c}0.054 \\
(0.236)\end{array}$ & $\begin{array}{c}0.784 \\
(0.391)\end{array}$ \\
\hline$J(20)$ & 8.947 & 9.299 & 6.111 \\
\hline
\end{tabular}

Standard errors using a four lag Newey-West covariance matrix are reported in brackets. Inflation is measured as changes in the GDP chain-type price index and output gap is obtained from the CBO. Four lags of gdp inflation, squared gdp inflation, cbo output gap, squared cbo output gap, the fed funds rate and consumer price inflation are included as instruments. $\mathrm{J}(\mathrm{m})$ refers to the statistics of Hansen's test for $m$ overidentifying restrictions which is distributed as a $\chi^{2}(m)$ under the null hypothesis of valid overidentifying restrictions. 
Table 2: Testing for symmetric policy preferences

- Wald-type test of the joint null hypothesis $\alpha=\gamma=0$ -

\begin{tabular}{ccc}
\hline \hline $\boldsymbol{W}(2)$ & $60: 1-79: 2$ & $82: 4-01: 4$ \\
\hline Baseline Estimates & 72.400 & 34.383 \\
Cpi Inflation & 39.731 & 33.510 \\
Detrended Output gap & 95.844 & 73.214 \\
& & \\
Interest Rate & & \\
Smoothing & 46.425 & \\
\hline \hline
\end{tabular}

$\mathrm{W}(n)$ is the Wald test for $n$ parameter restrictions, which is distributed as a $\chi^{2}(n)$ under the joint null hypothesis $\mathrm{c} 4=\mathrm{c} 5=0$. The latter is equivalent to the original null of symmetric central bank preferences, $\alpha=\gamma=0$. The joint null is rejected at the $1 \%$ significance level whenever $\mathrm{W}(2)>9.210$ and at the $5 \%$ whenever $\mathrm{W}(2)>5.991$. 
Table 3: Reaction Function and Policy Preferences Estimates

- alternative measure of inflation -

\begin{tabular}{|c|c|c|}
\hline & 1960:1 - 1979:2 & $1982: 42001: 4$ \\
\hline const & $\begin{array}{c}4.898 \\
(0.100)\end{array}$ & $\begin{array}{c}6.267 \\
(0.207)\end{array}$ \\
\hline$c 1$ & $\begin{array}{c}0.648 \\
(0.019)\end{array}$ & $\begin{array}{c}1.095 \\
(0.221)\end{array}$ \\
\hline$c 2$ & $\begin{array}{c}0.267 \\
(0.026)\end{array}$ & $\begin{array}{c}0.543 \\
(0.084)\end{array}$ \\
\hline$c 3$ & $\begin{array}{c}0.027 \\
(0.005)\end{array}$ & $\begin{array}{c}0.117 \\
(0.073)\end{array}$ \\
\hline$c 4$ & $\begin{array}{l}-0.007 \\
(0.008)\end{array}$ & $\begin{array}{l}-0.160 \\
(0.075)\end{array}$ \\
\hline$\pi^{*}$ & $\begin{array}{c}4.432 \\
-\end{array}$ & $\begin{array}{c}2.585 \\
-\end{array}$ \\
\hline$\gamma$ & $\begin{array}{c}-0.050 \\
(0.060)\end{array}$ & $\begin{array}{c}-0.590 \\
(0.310)\end{array}$ \\
\hline$\alpha$ & $\begin{array}{c}0.082 \\
(0.015)\end{array}$ & $\begin{array}{c}0.214 \\
(0.147)\end{array}$ \\
\hline$J(20)$ & 10.980 & 10.123 \\
\hline
\end{tabular}

Standard errors using a four lag Newey-West covariance matrix are reported in brackets. Inflation is measured as changes in the consumer price index and output gap is obtained from the CBO. Four lags of cpi inflation, squared cpi inflation, cbo output gap, squared cbo output gap, the fed funds rate and gdp chain-type inflation are included as instruments. $\mathbf{J}(m)$ refers to the statistics of Hansen's test for $m$ overidentifying restrictions which is distributed as a $\chi^{2}(m)$ under the null hypothesis of valid overidentifying restrictions. 
Table 4: Reaction Function and Policy Preferences Estimates

- alternative measure of output gap -

\begin{tabular}{|c|c|c|}
\hline & 1960:1 - 1979:2 & $1982: 42001: 4$ \\
\hline const & $\begin{array}{c}4.787 \\
(0.143)\end{array}$ & $\begin{array}{c}7.694 \\
(0.254)\end{array}$ \\
\hline$c 1$ & $\begin{array}{c}0.681 \\
(0.039)\end{array}$ & $\begin{array}{c}1.417 \\
(0.185)\end{array}$ \\
\hline$c 2$ & $\begin{array}{c}0.245 \\
(0.026)\end{array}$ & $\begin{array}{c}0.411 \\
(0.038)\end{array}$ \\
\hline$c 3$ & $\begin{array}{c}0.130 \\
(0.013)\end{array}$ & $\begin{array}{c}-0.364 \\
(0.150)\end{array}$ \\
\hline$c 4$ & $\begin{array}{c}-0.035 \\
(0.018)\end{array}$ & $\begin{array}{c}-0.215 \\
(0.026)\end{array}$ \\
\hline$\pi^{*}$ & $\begin{array}{c}4.432 \\
-\end{array}$ & $\begin{array}{c}2.585 \\
-\end{array}$ \\
\hline$\gamma$ & $\begin{array}{c}-0.290 \\
(0.144)\end{array}$ & $\begin{array}{l}-1.048 \\
(0.152)\end{array}$ \\
\hline$\alpha$ & $\begin{array}{c}0.382 \\
(0.045)\end{array}$ & $\begin{array}{c}-0.514 \\
(0.171)\end{array}$ \\
\hline$J(20)$ & 8.260 & 8.879 \\
\hline
\end{tabular}

Standard errors using a four lag Newey-West covariance matrix are reported in brackets. Inflation is measured as changes in the GDP chain-type price index and output gap is obtained from regressing output on a constant and a quadratic trend. Four lags of gdp inflation, squared gdp inflation, detrended output gap, squared detrended output gap, the fed funds rate and consumer price inflation are included as instruments. $\mathrm{J}(\mathrm{m})$ refers to the statistics of Hansen's test for $m$ overidentifying restrictions which is distributed as a $\chi^{2}(m)$ under the null hypothesis of valid overidentifying restrictions. 

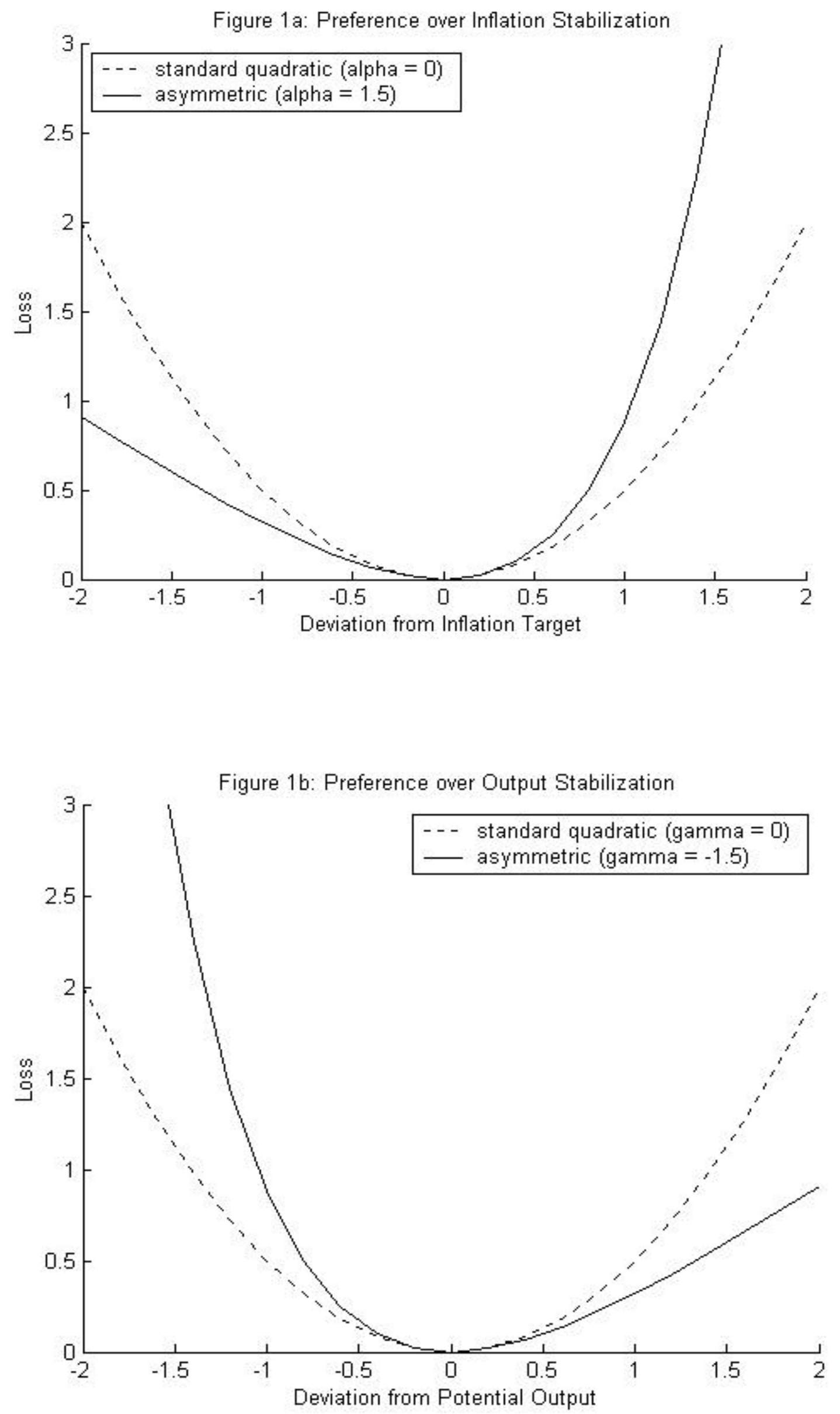
Figure 2: The Policy Response to Inflation Gap over the Greenspan era

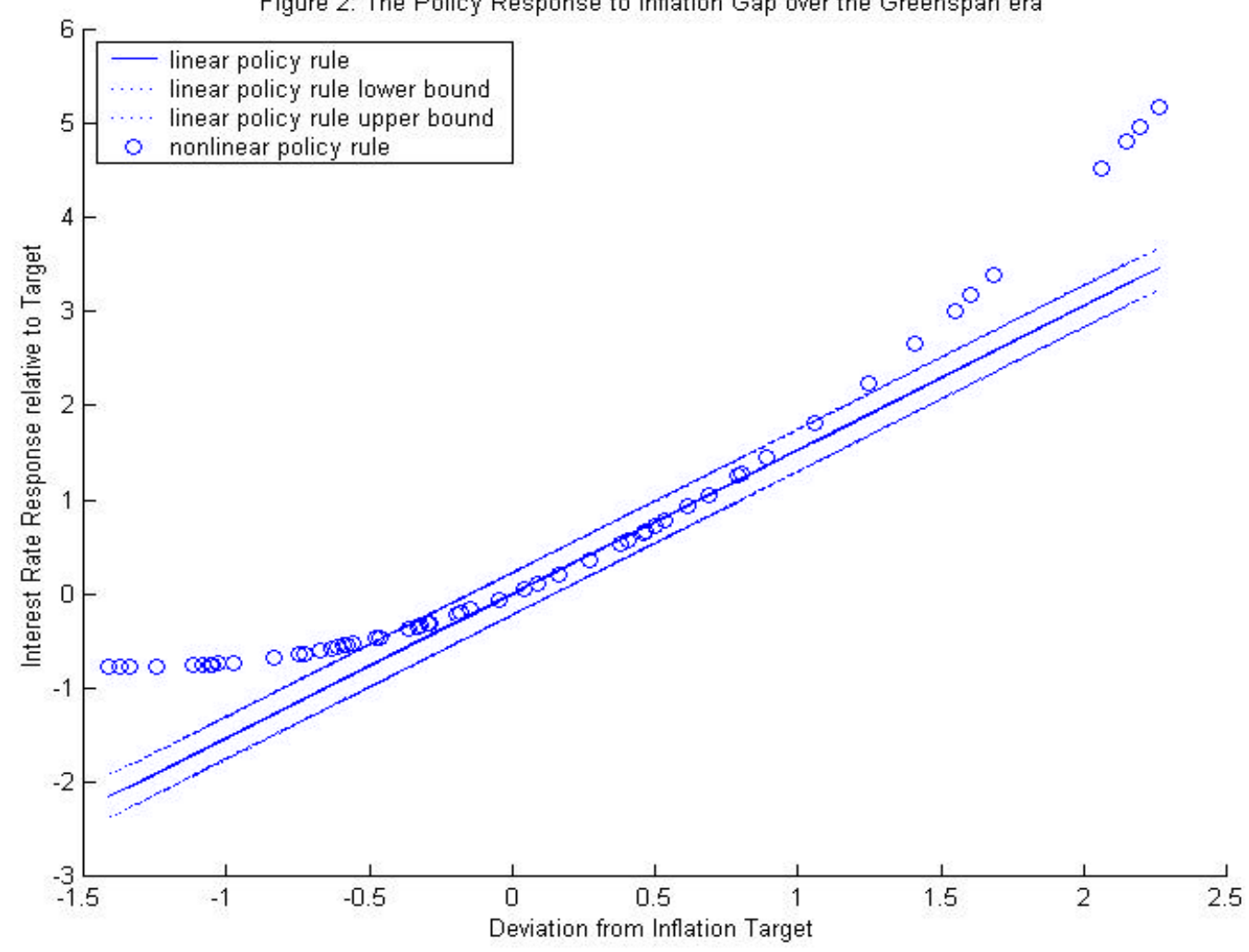

The linear policy rule, $\mathrm{i}_{\mathrm{t}}=$ const $+\mathrm{c}_{1}\left(\pi_{\mathrm{t}}-\pi^{*}\right)+\mathrm{c}_{2} \mathrm{y}_{\mathrm{t}}+\mathrm{v}_{\mathrm{t}}$, has been estimated with GMM using all instruments employed for the baseline case but the squared variables. The estimates are const $=$ 5.694 with s.e. $=0.128, \mathrm{c} 1=1.529$ with s.e. $=0.112$ and $\mathrm{c} 2=0.694$ with s.e. $=0.057$. The deviation from inflation target refers to the actual values of GDP chain-type index inflation observed over the period 1987:3 - 2001:4 using the sample mean, 2.423, as the target value.

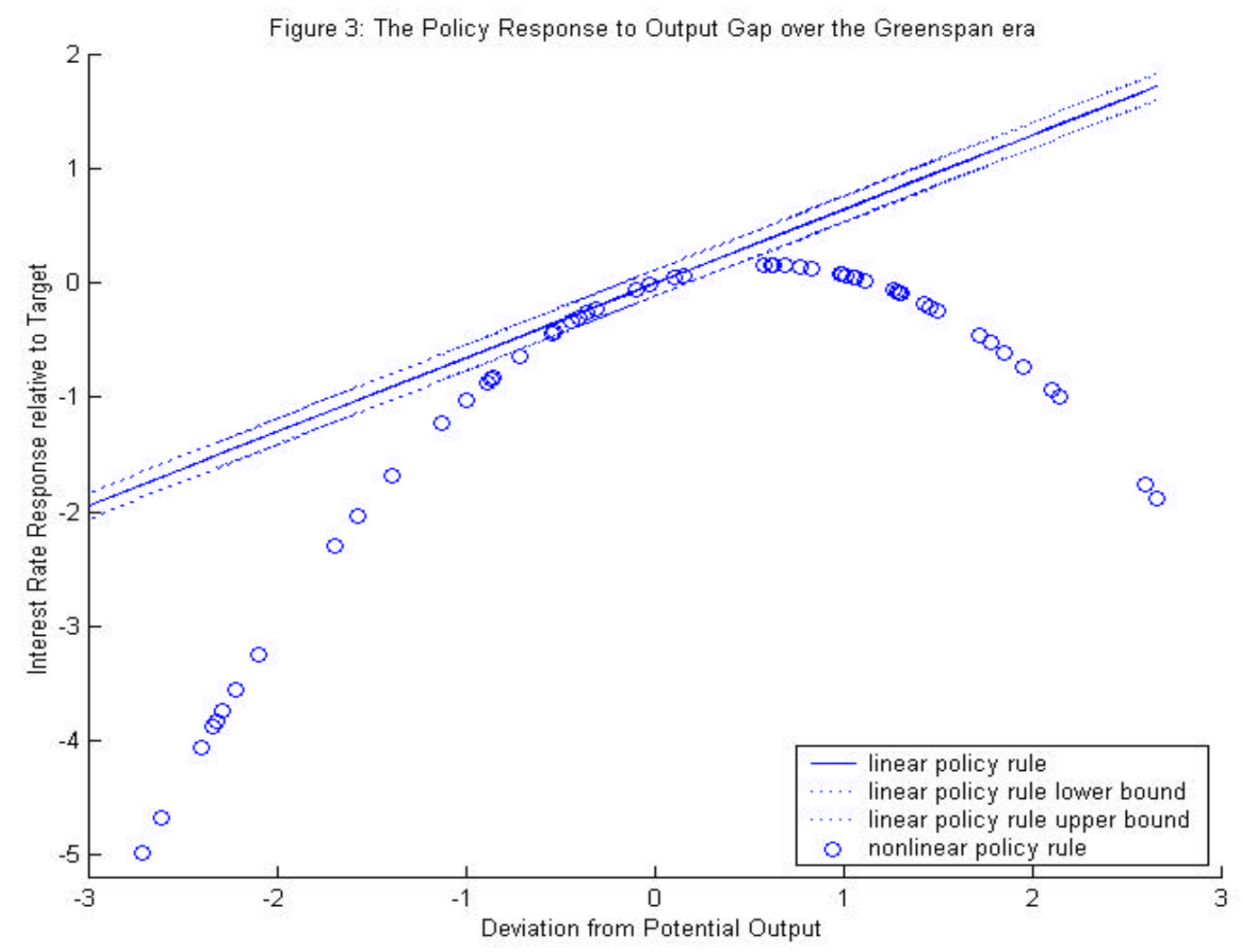

The linear policy rule, $\mathrm{i}_{\mathrm{t}}=$ const $+\mathrm{c}_{1}\left(\pi_{\mathrm{t}}-\pi^{*}\right)+\mathrm{c}_{2} \mathrm{y}_{\mathrm{t}}+v_{\mathrm{t}}$, has been estimated with GMM using all instruments employed for the baseline case but the squared variables. The estimates are const $=$ 5.694 with s.e. $=0.128, \mathrm{c} 1=1.529$ with s.e. $=0.112$ and $\mathrm{c} 2=0.694$ with s.e. $=0.057$. The deviation from potential output refers to the actual values of the Congressional Budget Office Series observed over the period 1987:3 - 2001:4. 